\title{
Prophylactic effects of hydroxychloroquine on the incidence of COVID-19 in patients with rheumatic arthritis: an observational cohort study
}

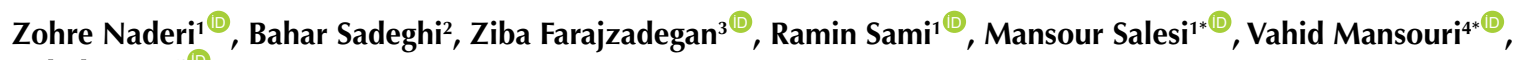 \\ Babak Amra ${ }^{5}$ \\ 'Department of Internal Medicine, Faculty of Medicine, Isfahan University of Medical Sciences, Isfahan, Iran \\ ${ }^{2}$ Student Research Committee, Faculty of Medicine, Isfahan University of Medical Sciences, Isfahan, Iran \\ ${ }^{3}$ Department of Community Medicine, Faculty of Medicine, Isfahan University of Medical Sciences, Isfahan, Iran \\ ${ }^{4}$ Digestive Diseases Research Institute, Shariati Hospital, Tehran University of Medical Sciences, Tehran, Iran \\ ${ }^{5}$ Bamdad Respiratory and Sleep Research Center, Pulmonary and Sleep Ward, Internal Medicine Department, Isfahan University of \\ Medical Sciences, Isfahan, Iran
}

*Correspondence to Mansour Salesi,

Email: Salesi@med.mui.ac.ir; Vahid Mansouri,

Email: Mansoury.vahid@gmail. com

Received 2 Jan 2021 Accepted 28 Feb. 2021 Published online 6 Apr. 2021

Keywords: COVID-19, Hydroxychloroquine, Prophylaxis, Rheumatic arthritis, Observational, Prospective

\begin{abstract}
Introduction: Rheumatoid arthritis (RA) is a systemic autoimmune disease with substantial morbidity and mortality Anti-malarial drugs like hydroxychloroquine are indicated in several rheumatic diseases such as RA. Some reports have suggested hydroxychloroquine for prevention of COVID-19.

Objectives: Whether hydroxychloroquine has prophylactic effects for COVID-19 in rheumatic patients.

Patients and Methods: In this multicenter cohort-based observational study the preventive effect of hydroxychloroquine regarding the incidence and severity of COVID-19 was investigated in patients with RA who referred to rheumatology clinics of academic hospitals of Isfahan between April and July 2020 and already have been treated with hydroxychloroquine for more than three months. Around 215 patients with RA and current use of hydroxychloroquine were recruited and followed for three months. Patients' information was gathered using the medical record or by phone call.

Results: The incidence of COVID-19 in this selected sample was $4.2 \%(n=9)$. Only one in nine patients needed hospitalization, without need for intubation or ICU care. Symptoms including dry cough, headache, body pain, malaise, dyspnea, fever, sore throat, chills, and chest pain, were reported to be statistically higher in COVID-19+ group.

Conclusion: In contrast to the mortality rate in the general population of Isfahan, Iran (4.8\% - until June 2020), no mortality has been reported in these patients. Therefore, it seems that the use of hydroxychloroquine has been able to reduce the incidence and severity of the disease after reaching steady-state levels. This finding has clinical importance, especially for rheumatic patients using immunomodulatory drugs.
\end{abstract}

\section{Introduction}

COVID-19 caused by the 2019 novel coronavirus (SARS-CoV-2) is characterized by a presence of different symptoms including fever, dry cough, dyspnea, fatigue, and some extra-pulmonary symptoms accompanied by lymphopenia (1). However, there is a spectrum from asymptomatic to critically ill condition in the COVID-19 pandemic that has affected approximately millions of people all around the world and caused many deaths, influencing almost every aspect of life (2).

Rheumatoid arthritis (RA) is a systemic autoimmune disease characterized by chronic inflammation of the joints that causes substantial cardiovascular, respiratory, musculoskeletal and endocrine morbidity and mortality (5-year survival of $80 \%$ ) (3). Conventional therapy for RA includes

\begin{abstract}
Key point
The long-term usage of hydroxychloroquine has an effective prophylactic impact on the incidence of COVID-19. It seems that hydroxychloroquine has been able to reduce the possibility of infection and reduce the severity of the disease in patients who continuously administered hydroxychloroquine for several months and its blood level has reached a steady state.
\end{abstract}

the administration of anti-inflammatory drugs, followed by disease-modifying antirheumatic drugs such as methotrexate, hydroxychloroquine, and sulfasalazine. Furthermore, in the case of acute disease flare-up, glucocorticoids can be used to relieve pain and swelling rapidly by controlling the inflammation (4).

Previous studies showed that the complex

\footnotetext{
Copyright $(\subset 2021$ The Author(s); Published by Nickan Research Institute. This is an open-access article distributed under the terms of the Creative Commons Attribution License (http://creativecommons.org/licenses/by/4.0), which permits unrestricted use, distribution, and reproduction in any medium, provided the original work is properly cited.
} 
relationship between infections and arthritis could be interpreted in two ways. The first way, in the general population, there is plenty of evidence on the role of pathogens in development of acute and chronic arthritis. The effects could be mediated by direct colonization or individual improper autoimmune reaction. The second way, is for the patients with autoimmune arthritis, in which inflammatory arthritis - like other inflammatory processes - could result in the disease flare-up (5-8).

Chloroquine and hydroxychloroquine are widely used as anti-malarial drugs with well-known immunomodulatory properties in which their indication of usage has been extended to several rheumatic diseases such as RA (9). Likewise, the ability of chloroquine as an anti-viral agent has been known since the late 1960s (10). Indeed, hydroxychloroquine in the body will concentrate on the intracellular parts including endosome and lysosome, and prevent viral replication as well as changing the binding of protein-S in SARS-COV-2.

Some reports have stated that hydroxychloroquine can be used to prevent COVID 19 in people exposed to the diseases. In this regard, there are some ongoing clinical trials to clarify the effect of hydroxychloroquine on postexposure cases (11).

\section{Objectives}

Considering the hard-to-control situation for designing a study to assess the prophylaxis effect of hydroxychloroquine, the cohort study on RA-patients who use hydroxychloroquine is valuable to find the drug prophylaxis effect. Therefore, we decided to investigate the preventive effects of hydroxychloroquine regarding the incidence of COVID-19 in patients with RA who already have been treated with hydroxychloroquine for more than three months.

\section{Patients and Methods}

\section{Study design and participants}

This multicenter cohort-based observational study was performed on patients with RA referring to rheumatology clinics of academic hospitals of Isfahan between April and July 2020. All known cases of RA were evaluated and ones with current use of hydroxychloroquine were enrolled in the study. All RA patients with the history of using hydroxychloroquine were included in the study except for those who were taking angiotensin-converting enzyme (ACE) inhibitors. Patients' information including demographic data and COVID-19 related information was gathered using the medical record or by phone call.

\section{Data collection and outcomes}

The information was as follow; age, gender, RA diseaseduration, type of residential building, drug history (hydroxychloroquine, azathioprine, methotrexate, prednisolone, other biological drugs; infliximab, adalimumab [CinnoRA], etanercept) along with the dosage and history of their usage, and other comorbidities (diabetes, hypertension, other cardiovascular diseases, obesity, end-stage renal disease and respiratory diseases). Additionally, COVID-19 symptoms including constitutional, respiratory and extra-pulmonary symptoms, history of exposure with the asymptomatic individual, length of the disease course, COVID-19 diagnostic polymerase chain reaction (PCR) result were gathered. In case of any suspicion for COVID-19 infection on calls, the COVID-19 PCR test was used to confirm the diagnose. Patients were divided into two groups according to the interviews; patients with RA who at least once diagnosed with COVID-19 based on the PCR test; and the RA patients without positive results for COVID-19 PCR test.

\section{Ethical issues}

The research followed the tenets of the Declaration of Helsinki. The Ethics Committee of Isfahan University of medical sciences approved this study (IR.MUI.MED. REC.1399.067). Accordingly, written informed consent was taken from all participants before any intervention. This study was extracted from the M.D thesis of Bahar Sadeghi at this university (Thesis\#199038).

\section{Statistical analysis}

Descriptive statistics including frequency for qualitative variables and mean \pm standard deviation for quantitative variables were used. To compare the dichotomous variables, chi-square or Fisher's exact test was used. Logistic regression was employed to assess the association between different variables and infection with COVID-19. Data were analyzed using SPSS software version 22 (IBM SPSS Statistics for Windows, Version 22.0 Armonk, NY: IBM Crop.). The significance level was considered 0.05 for each test.

\section{Results}

Overall, 954 patients with rheumatic disease were evaluated. Around 632 of total patients have other rheumatic diseases rather than RA. About 322 patients had RA and in phone contact, 64 patients were not reachable or did not tend to enroll in the study. Among the 258 remaining patients, 43 patients did not use hydroxychloroquine as part of their treatment or discontinue their usage. Finally, 215 patients with the diagnosis of RA by the rheumatologist and current use of hydroxychloroquine were entered in the study. The flow diagram of the population selection is shown in Figure 1.

The characteristics of patients with RA have been shown in Table 1. The mean age of the participants was $51.09 \pm$ 12.01 years. Forty (18.6\%) of them were male. They had RA for an average of $3.41 \pm 2.66$ years. The treatment regimen of $80(37.2 \%)$ and $31(14.4 \%)$ of them, in addition to hydroxychloroquine, include prednisolone and methotrexate, respectively. Their most common 


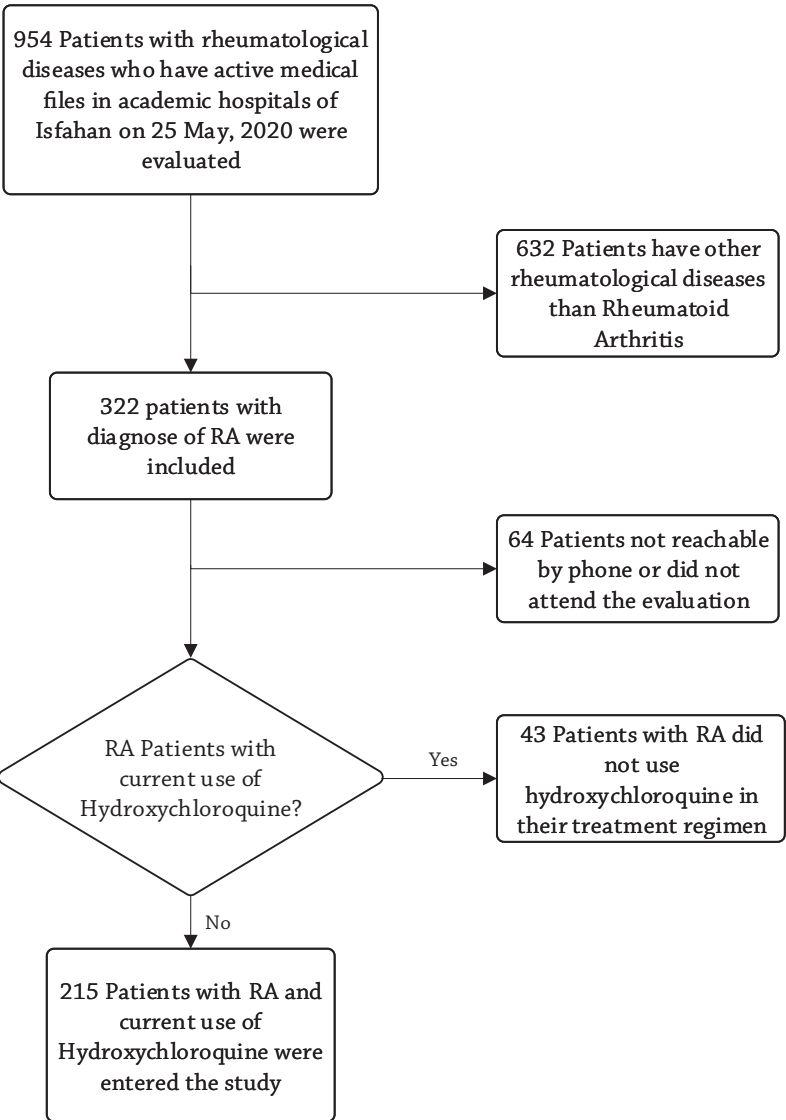

Figure 1. Flow diagram of the enrolled participants.

underlying disease (except for RA) were hypertension, diabetes, and cardiovascular disorders. The most common associated symptoms of COVID-19 in this population were sore throat, dry cough, fever, and chills, in the order of frequency. On average, patients with these symptoms experience them for $12.75 \pm 2.76$ days. The incidence of COVID-19 in this selected sample was $4.2 \%(n=9)$ (Table 1).

For evaluating the contributing factors for the incidence of COVID-19, we divided the population into two groups including COVID-19+ ${ }^{+}$and COVID-19-, as described above. They were no significant difference between cases and controls regarding age and gender. Additionally, underlying diseases were not significantly different between them, except for diabetes with a higher incidence in the patients with COVID-19 (odds ratio [OR] $=7.048$, 95\% CI: 7.048-28.298, $P=0.002$ ). Furthermore, two groups were not significantly different regarding the number of years of having RA. The usage of biological drugs (mainly CinnoRA and etanercept) was significantly higher in the COVID-19 group (OR=3.571, $P<0.001)$. Due to few numbers of COVID-19 cases in this population several of the associated symptoms including dry cough, headache, body pain, malaise, dyspnea, fever, sore throat, chills, and chest pain, were reported to be statistically higher in COVID-19+ group. As expected, the number of
Table 1. Characteristics of enrolled patients with rheumatic arthritis $(\mathrm{n}=215)$

\begin{tabular}{|c|c|}
\hline Variables & Mean \\
\hline Age, mean (median [IQR]) & $51.09(52[43-60])$ \\
\hline \multicolumn{2}{|l|}{ Gender, No (\%) } \\
\hline Male & $40(18.6 \%)$ \\
\hline Female & $175(81.4 \%)$ \\
\hline \multicolumn{2}{|l|}{ Symptoms, No (\%) } \\
\hline Dry cough & $14(6.5 \%)$ \\
\hline Headache & $2(0.9 \%)$ \\
\hline Body pain & $6(2.8 \%)$ \\
\hline Nausea & $1(0.5 \%)$ \\
\hline Vomiting & $1(0.5 \%)$ \\
\hline Diarrhea & $3(1.4 \%)$ \\
\hline Malaise & $3(1.4 \%)$ \\
\hline Dyspnea & $7(3.3 \%)$ \\
\hline Fever & $13(6 \%)$ \\
\hline Sore throat & $18(8.4 \%)$ \\
\hline Chills & $10(4.7 \%)$ \\
\hline Anosmia & $1(0.5 \%)$ \\
\hline Chest Pain & $3(1.4 \%)$ \\
\hline \multicolumn{2}{|l|}{ Drugs used, No (\%) } \\
\hline Hydroxychloroquine & $215(100 \%)$ \\
\hline Prednisolone & $80(37.2 \%)$ \\
\hline Biologics & $3(1.4 \%)$ \\
\hline Azathioprine & $2(0.9 \%)$ \\
\hline Methotrexate & $31(14.4 \%)$ \\
\hline \multicolumn{2}{|l|}{ Underlying disorders, No (\%) } \\
\hline Cardiovascular disorders & $17(7.9 \%)$ \\
\hline Hypertension & $38(17.6 \%)$ \\
\hline Respiratory disorders & $13(6 \%)$ \\
\hline Diabetes & $23(10.6 \%)$ \\
\hline Morbid Obesity (BMI>40) & $5(2.3 \%)$ \\
\hline Dialysis & $1(0.5 \%)$ \\
\hline $\begin{array}{l}\text { Mean duration of RA (y), mean (median } \\
{[\text { IQR]) }}\end{array}$ & $3.41(3[2-4])$ \\
\hline \multicolumn{2}{|l|}{ Number of symptoms, No (\%) } \\
\hline 0 & $175(81.4 \%)$ \\
\hline 1 & $19(8.8 \%)$ \\
\hline 2 & $10(4.7 \%)$ \\
\hline 3 & $7(3.3 \%)$ \\
\hline$>4$ & $4(1.9 \%)$ \\
\hline \multicolumn{2}{|l|}{ Confirmed COVID-19 } \\
\hline Yes & $9(4.2 \%)$ \\
\hline No & $207(96.3 \%)$ \\
\hline $\begin{array}{l}\text { The average number of days with } \\
\text { symptoms }(n=9) \text {, mean (median }[\text { [QR]) }\end{array}$ & $\begin{array}{l}12.75(14[11- \\
14.75])\end{array}$ \\
\hline
\end{tabular}

COVID-19 associated symptoms in the COVID-19 group was significantly higher, compared with the control group. Figure 2 shows the distribution of common symptoms of the COVID-19, including fever, dry cough, fever, and other associated symptoms in the two groups. However, the frequency of these symptoms was not significantly 


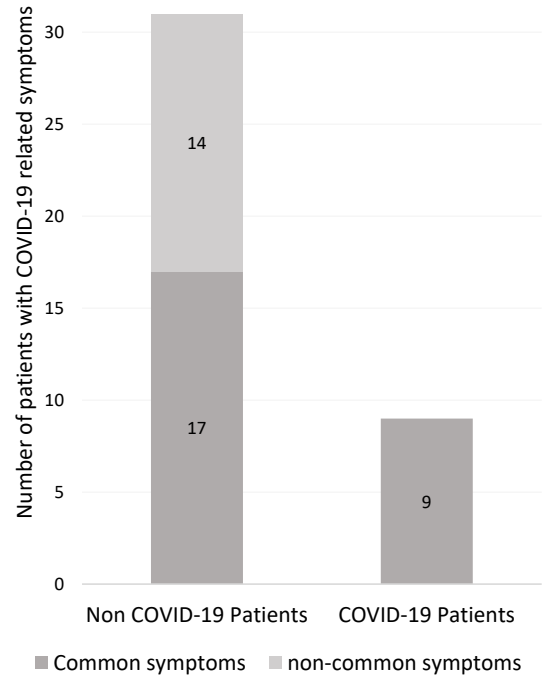

Figure 2. Number of patients with at least one of common symptoms of the COVID-19 - including dyspnea or dry cough or fever- and other associated symptoms in two groups.

different between the two groups $(P=0.955)$. Figure 3 shows the ORs of most common demographic characteristics and drug/symptoms for the incidence of COVID-19 (Figure 2, Table 2).

Table 3 shows the individual characteristics of the confirmed cases of COVID-19 in this study. The mean age was $53.56 \pm 13.34$ years since 8 out of $9(88.8 \%)$ of them were female. Their most common symptoms were fever, dry cough, and sore throat and the most common underlying diseases were diabetes and hypertension. Their mean BMI was $23.82 \pm 4.15 \mathrm{~kg} / \mathrm{m}^{2}$ and two of them were overweight and just one of them was obese. However, none of them was morbidly obese. Mean RA-disease-duration was $4 \pm 1.87$ years. Only one patient was smoker, however, none of them reported previous respiratory disorders. Only one of them hospitalized for her disease, but there was no need for intubation of ICU care during her 6-hours hospitalization.

\section{Discussion}

This study, on RA patients, showed that only $4.2 \%$ of individuals undergoing hydroxychloroquine for at least three months were affected by SARS-COV2. Contrary to what is commonly seen in the general population, where typically $80 \%$ of patients are asymptomatic or have mild symptoms, in our patients with COVID-19, 77.7\% had three or more symptoms associated with the disease (12).

Statistics showed that $20 \%$ of patients in the community need to be hospitalized due to severe form of COVID-19. This proportion was even higher in rheumatic patients (31.6\%) (13), while this study showed that only one in nine RA-patients required admission with no need to be intubated or ICU care. Furthermore, the mortality rate in the general population of Isfahan, Iran was $4.8 \%$ until June 2020 (14), while in these patients, no mortality was

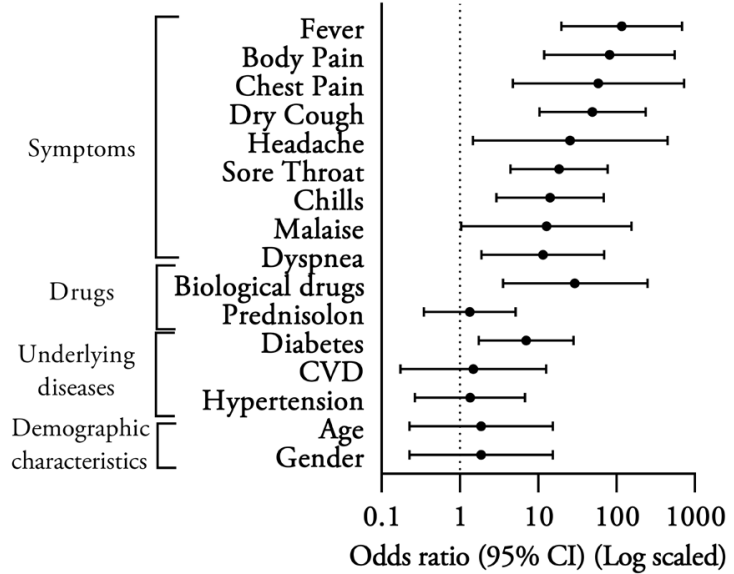

Figure 3. Odds ratios of most common demographic characteristics and drug/ symptoms for the incidence of COVID-19.

observed. Therefore, it seems that hydroxychloroquine has been able to reduce the possibility of infection and reduce the severity of the disease in patients who continuously administered hydroxychloroquine for several months and its blood level has reached a steady state. According to previous studies, hydroxychloroquine takes an average of three to six months to reach steady-state levels in the blood (15).

Balevic et al examined the serum hydroxychloroquine of rheumatoid patients such as lupus and concluded that the blood level of the drug is less than the intended therapeutic dose for COVID-19 patients. Their study also showed that patients who receiving hydroxychloroquine for longtime have tissue concentrations much higher than the blood levels (16). Although the exact therapeutic level of hydroxychloroquine is still unclear, it it has been demonstrated that hydroxychloroquine with daily dosage of $800 \mathrm{mg}$ could significantly reduce the viral load and increase the rate of PCR-negative patients (17). The abovementioned results showed rheumatic patients with at least three months of hydroxychloroquine usage could benefit from the prophylactic effect of high tissue concentration of hydroxychloroquine. This study demonstrated the prophylactic effect of hydroxychloroquine by comparing the COVID-19 incidence rate in RA patients (4.2\%) and the general population (approximately 27.5\%) (14).

However, the data is not completely consistent. A recent large multicenter cohort study showed no beneficial effect of hydroxychloroquine regarding hospitalization and in-hospital mortality $(18,19)$. Moreover, in another prospective study in France, the clinical course of 17 patients with systemic lupus erythematosus (SLE) who got COVID-19 was described. They did not find a significant prophylactic effect of hydroxychloroquine for preventing COVID-19, or at least its severe form in patients with SLE and long-term use of hydroxychloroquine (20). Another study on 120 patients with SLE demonstrated that the 
Table 2. The association between demographic characteristics and symptoms with the incidence of COVID-19

\begin{tabular}{|c|c|c|c|c|}
\hline Variables & Non COVID-19 patients $(n=206)$ & COVID-19 patients $(n=9)$ & Exp(B) or Odds ratio & $P$ \\
\hline Age, mean (SD) & $51.09(12.01)$ & $53.56(13.34)$ & $1.017^{\mathrm{b}}$ & 0.548 \\
\hline \multicolumn{5}{|l|}{ Gender, No. (\%) } \\
\hline Male & $39(18.9 \%)$ & $1(11.1 \%)$ & $0.547^{\mathrm{a}}(\mathrm{M} / \mathrm{F})$ & 0.555 \\
\hline Female & $167(81.1 \%)$ & $8(88.9 \%)$ & & \\
\hline \multicolumn{5}{|l|}{ Symptoms, No. (\%) } \\
\hline Dry cough & $8(3.9 \%)$ & $6(66.7 \%)$ & $49.5^{\mathrm{a}}$ & $<0.001^{*}$ \\
\hline Headache & $1(0.5 \%)$ & $1(11.1 \%)$ & $25.625^{a}$ & $0.001^{*}$ \\
\hline Body pain & $2(1 \%)$ & $4(44.4 \%)$ & $81.6^{\mathrm{a}}$ & $<0.001^{*}$ \\
\hline Nausea & $0(0 \%)$ & $1(11.1 \%)$ & - & - \\
\hline Vomiting & $0(0 \%)$ & $1(11.1 \%)$ & - & - \\
\hline Diarrhea & $0(0 \%)$ & $1(11.1 \%)$ & - & - \\
\hline Malaise & $2(1 \%)$ & $1(11.1 \%)$ & $12.75^{\mathrm{a}}$ & $0.011^{*}$ \\
\hline Dyspnea & $5(2.4 \%)$ & $2(22.2 \%)$ & $11.486^{\mathrm{a}}$ & $0.001^{*}$ \\
\hline Fever & $6(2.9 \%)$ & $7(77.8 \%)$ & $116.66^{\mathrm{a}}$ & $<0.001^{*}$ \\
\hline Sore throat & $13(6.3 \%)$ & $5(55.6 \%)$ & $18.558^{a}$ & $<0.001^{*}$ \\
\hline Chills & $7(3.4 \%)$ & $3(33.3 \%)$ & $14.214^{\mathrm{a}}$ & $<0.001^{*}$ \\
\hline Anosmia & $0(0 \%)$ & $1(11.1 \%)$ & - & $<0.001^{*}$ \\
\hline Chest pain & $1(0.5 \%)$ & $2(22.2 \%)$ & $58.571^{\mathrm{a}}$ & $<0.001^{*}$ \\
\hline \multicolumn{5}{|l|}{ Drugs used, No. (\%) } \\
\hline Hydroxychloroquine & $207(100 \%)$ & $8(100 \%)$ & - & - \\
\hline Prednisolone & $77(37.4 \%)$ & $3(33.3 \%)$ & $0.837^{\mathrm{a}}$ & 0.806 \\
\hline Biologics & $2(1 \%)$ & $2(22.2 \%)$ & $29.411^{\text {a }}$ & $<0.001^{*}$ \\
\hline Azathioprine & $2(1 \%)$ & $0(0 \%)$ & - & $<0.001^{*}$ \\
\hline Methotrexate & $29(14.1 \%)$ & $2(22.2 \%)$ & $1.745^{\mathrm{a}}$ & 0.385 \\
\hline \multicolumn{5}{|l|}{ Underlying disorders, No. (\%) } \\
\hline Cardiovascular disorders & $16(7.8 \%)$ & $1(11.1 \%)$ & $1.484^{\mathrm{a}}$ & 0.716 \\
\hline Hypertension & $36(17.5 \%)$ & $2(22.2 \%)$ & $1.349^{\mathrm{a}}$ & 0.715 \\
\hline Respiratory disorders & $13(6.3 \%)$ & $0(0 \%)$ & - & 0.437 \\
\hline Diabetes & $21(10.2 \%)$ & $4(44.4 \%)$ & $7.04^{8} \mathrm{a}$ & $0.002^{*}$ \\
\hline Morbid Obesity (BMI>40) & $5(2.4 \%)$ & $0(0 \%)$ & - & 0.636 \\
\hline Dialysis & $1(0.5 \%)$ & $0(0 \%)$ & - & 0.834 \\
\hline Mean duration of RA (y), mean (SD) & $3.39(2.69)$ & $4(1.87)$ & $1.065^{\mathrm{b}}$ & 0.507 \\
\hline \multicolumn{5}{|l|}{ Number of symptoms, No. (\%) } \\
\hline 0 & $175(85.5 \%)$ & $0(0 \%)$ & & $<0.001^{*}$ \\
\hline 1 & $19(9.2 \%)$ & $0(0 \%)$ & & \\
\hline 2 & $8(3.9 \%)$ & $2(22.2 \%)$ & & \\
\hline 3 & $4(1.9 \%)$ & $3(33.3 \%)$ & & \\
\hline$>4$ & $0(0 \%)$ & $4(44.4 \%)$ & & \\
\hline
\end{tabular}

a Data obtained by the chi-square test.

${ }^{\mathrm{b}}$ Data obtained by logistic regression test.

frequency of COVID-19 related symptoms was not significantly different between patients with and without use of hydroxychloroquine (21). However, in contrast to retrospective studies that recruited patients with rheumatic disorders and COVID-19 reported mixed results, our study was prospectively and followed a relatively high number of patients with arthritis rheumatoid and monitor the rate of COVID-19 incidence and its severity. Moreover, several high-quality clinical trials for evaluating the prophylactic effect of hydroxychloroquine are still underway (https:// www.clinicaltrials.gov) (22).
Finding out how the rheumatic patients could be affected by COVID-19 is of special importance for rheumatologists. First of all, these patients are more prone to infections, due to treating with immunomodulatory drugs (23). Moreover, some of their related drugs, such as antimalarials, anti-IL-6 agents and JAK inhibitors might have preventative effects for COVID-19 (24).

The major strength of this study was the considerable number of rheumatic patients. In addition, to the best of our knowledge, this study was the first study to evaluate the prophylactic effect of hydroxychloroquine in RA patients. 
Table 3. Individual characteristics of the confirmed cases of COVID-19

\begin{tabular}{|c|c|c|c|c|c|c|c|c|c|}
\hline Gender & Age & Symptoms & $\begin{array}{l}\text { Drugs used (Except } \\
\text { Hydroxychloroquine) }\end{array}$ & Risk Factors & $\begin{array}{l}\text { RA } \\
\text { duration }\end{array}$ & $\begin{array}{l}\text { COVID-19 } \\
\text { duration }\end{array}$ & $\begin{array}{l}\text { Hours of Hospitalization } \\
\text { (need for supplemental } \\
\text { oxygen or ICU care) }\end{array}$ & $\begin{array}{l}\text { BMI } \\
\left(\mathrm{kg} / \mathrm{m}^{2}\right)\end{array}$ & Smoking \\
\hline Female & 56 & $\begin{array}{l}\text { Dry cough and Sore } \\
\text { throat }\end{array}$ & $\begin{array}{l}\text { Metformin and drug } \\
\text { for hypertension }\end{array}$ & $\begin{array}{l}\text { Hypertension and } \\
\text { diabetes }\end{array}$ & 3 & 13 & Negative & 22.4 & Negative \\
\hline Female & 57 & $\begin{array}{l}\text { Dry cough, body pain, } \\
\text { fever, chills and chest } \\
\text { pain }\end{array}$ & Prednisolone & $\begin{array}{l}\text { Cardiovascular } \\
\text { disorders, } \\
\text { hypertension and } \\
\text { diabetes }\end{array}$ & 5 & 14 & $\begin{array}{l}6 \text { hours (No need for } \\
\text { Supplemental } \mathrm{O}_{2} \text { or ICU } \\
\text { care) }\end{array}$ & 24.21 & Negative \\
\hline Female & 69 & Fever and chills & $\begin{array}{l}\text { Drugs for diabetes and } \\
\text { hypertension }\end{array}$ & $\begin{array}{l}\text { Hypertension and } \\
\text { diabetes }\end{array}$ & 7 & 15 & Negative & 31.11 & Negative \\
\hline Female & 39 & $\begin{array}{l}\text { Fever, chills, and } \\
\text { anosmia }\end{array}$ & None & None & 3 & 14 & Negative & 18.77 & Negative \\
\hline Male & 63 & $\begin{array}{l}\text { Dry cough, fever, and } \\
\text { sore throat }\end{array}$ & None & None & 5 & 7 & Negative & 28.37 & Positive \\
\hline Female & 38 & $\begin{array}{l}\text { Dry cough, body pain, } \\
\text { fever, and sore throat }\end{array}$ & $\begin{array}{l}\text { Methotrexate and } \\
\text { prednisolone }\end{array}$ & None & 3 & 10 & Negative & 22.47 & Negative \\
\hline Female & 62 & $\begin{array}{l}\text { Dry cough, dyspnea, } \\
\text { and sore throat }\end{array}$ & $\begin{array}{l}\text { Prednisolone and } \\
\text { etanercept }\end{array}$ & Diabetes & 3 & 14 & Negative & 18.17 & Negative \\
\hline Female & 65 & $\begin{array}{l}\text { Dry cough, headache, } \\
\text { body pain, malaise and } \\
\text { fever }\end{array}$ & $\begin{array}{l}\text { Methotrexate and } \\
\text { prednisolone }\end{array}$ & None & 6 & 14 & Negative & 25.42 & Negative \\
\hline Female & 33 & $\begin{array}{l}\text { Body pain, fever, sore } \\
\text { throat, chest pain, } \\
\text { nausea, vomiting, } \\
\text { diarrhea, dyspnea }\end{array}$ & Adalimumab & None & 1 & 21 & Negative & 23.43 & Negative \\
\hline
\end{tabular}

\section{Conclusion}

In contrast to the mortality rate in the general population of Isfahan, Iran (4.8\% - until June 2020), no mortality has been reported in these patients. Therefore, it seems that the use of hydroxychloroquine has been able to reduce the incidence and severity of the disease after reaching steadystate levels.

\section{Limitations and strengths}

The major limitation of this study was the unreliability of patients' self-reported suspected exposures with COVID-19 patients. The results were not reliable enough to be reported. Hence, it is unclear to what extent each person has been exposed to SARS-COV-2 sources. Therefore, similar studies on the other subgroups of the rheumatic disease in other communities can unleash the effect of some confounding factors and lead researchers to a more accurate conclusion.

\section{Acknowledgments}

We are thankful to the receptionists of rheumatology clinics of ALZahra, Noor and Ali-Asghar hospitals for their cooperation and special thanks to all the families who kindly helped us in gathering information.

\section{Authors' contribution}

ZN and MS contributed to the study conception and design. Material preparation, data collection and analysis were performed by $\mathrm{ZN}$, $\mathrm{BS}, \mathrm{ZF}, \mathrm{MS}$ and $\mathrm{VM}$. The first draft of the manuscript was written by $\mathrm{VM}$ and $\mathrm{BS}$ and $\mathrm{ZN}, \mathrm{MS}, \mathrm{RS}$ and BA left some comments on previous versions of the manuscript. All authors read and approved the final manuscript.
Conflicts of interest

None to be declared.

Ethical considerations

The authors observed the ethical issues including plagiarism, data fabrication and publication duplication.

\section{Funding/Support}

This study was funded by Isfahan University of Medical Sciences (Grant \# 199038).

References

1. Lai CC, Shih TP, Ko WC, Tang HJ, Hsueh PR. Severe acute respiratory syndrome coronavirus 2 (SARS-CoV-2) and coronavirus disease-2019 (COVID-19): The epidemic and the challenges. Int J Antimicrob Agents. 2020;55:105924. doi: 10.1016/j.ijantimicag.2020.105924.

2. Wang L, Wang Y, Ye D, Liu Q. Review of the 2019 novel coronavirus (SARS-CoV-2) based on current evidence. Int J Antimicrob Agents. 2020;55:105948. doi: 10.1016/j. ijantimicag.2020.105948.

3. Loppenthin K, Esbensen BA, Ostergaard M, Ibsen R, Kjellberg J, Jennum P. Morbidity and mortality in patients with rheumatoid arthritis compared with an age- and sex-matched control population: A nationwide register study. J Comorb. 2019;9:2235042X19853484. doi: 10.1177/2235042X19853484.

4. Smolen JS, Aletaha D, Koeller M, Weisman MH, Emery P. New therapies for treatment of rheumatoid arthritis. Lancet. 2007;370:1861-74. doi: 10.1016/S0140-6736(07)60784-3.

5. Favalli EG, Ingegnoli F, De Lucia O, Cincinelli G, Cimaz R, Caporali R. COVID-19 infection and rheumatoid arthritis: Faraway, so close! Autoimmun Rev. 2020;19:102523. doi: 10.1016/j.autrev.2020.102523.

6. Mathew AJ, Ravindran V. Infections and arthritis. Best Pract Res Clin Rheumatol. 2014:935-59. doi: 10.1016/j. 
berh.2015.04.009.

7. Bogdanos DP, Smyk DS, Invernizzi P, Rigopoulou El, Blank $\mathrm{M}$, Pouria $\mathrm{S}$, et al. Infectome: a platform to trace infectious triggers of autoimmunity. Autoimmun Rev. 2013;12:726-40. doi: 10.1016/j.autrev.2012.12.005

8. Listing J, Gerhold K, Zink A. The risk of infections associated with rheumatoid arthritis, with its comorbidity and treatment. Rheumatology (Oxford). 2013;52:53-61. doi: 10.1093/ rheumatology/kes305.

9. Haladyj E, Sikora M, Felis-Giemza A, Olesinska M. Antimalarials - are they effective and safe in rheumatic diseases? Reumatologia. 2018;56:164-73. doi: 10.5114/ reum.2018.76904.

10. Devaux CA, Rolain JM, Colson P, Raoult D. New insights on the antiviral effects of chloroquine against coronavirus: what to expect for COVID-19? Int J Antimicrob Agents. 2020;55:105938. doi: 10.1016/j.ijantimicag.2020.105938.

11. Pourdowlat G, Panahi P, Pooransari P, Ghorbani F. Prophylactic Recommendation for Healthcare Workers in COVID-19 Pandemic. Adv J Emergy Med. 2020;4:e39-e. DOI: 10.22114/ ajem.v0i0.362

12. Singhal T. A Review of Coronavirus Disease-2019 (COVID-19). Indian J Pediatr. 2020;87:281-6. doi: 10.1007/s12098-02003263-6.

13. Pablos JL, Galindo M, Carmona L, Lledo A, Retuerto M, Blanco R, et al. Clinical outcomes of hospitalised patients with COVID-19 and chronic inflammatory and autoimmune rheumatic diseases: a multicentric matched cohort study. Ann Rheum Dis. 2020;79:1544-9. doi: 10.1136/ annrheumdis-2020-218296.

14. Janani M, Beheshti-Nia F, Ahmadi H, Khazeni A, Yadegarafar G. Epidemiological Features and Hotspot of COVID-19 in Isfahan Province of Iran: Results of A Cohort Study. Research Square; 2020. doi: 10.21203/rs.3.rs-38143/v1.

15. Tett SE, Cutler DJ, Day RO, Brown KF. Bioavailability of hydroxychloroquine tablets in healthy volunteers. $\mathrm{Br} J \mathrm{Clin}$ Pharmacol. 1989;27:771-9. doi: 10.1111/j.1365-2125.1989. tb03439.x.

16. Balevic SJ, Hornik CP, Green TP, Clowse MEB, Gonzalez $D$, Maharaj AR, et al. Hydroxychloroquine in Patients with Rheumatic Disease Complicated by COVID-19: Clarifying
Target Exposures and the Need for Clinical Trials. J Rheumatol. 2020. doi: 10.3899/jrheum.200493.

17. Garcia-Cremades M, Solans BP, Hughes E, Ernest JP, Wallender E, Aweeka F, et al. Optimizing Hydroxychloroquine Dosing for Patients With COVID-19: An Integrative Modeling Approach for Effective Drug Repurposing. Clin Pharmacol Ther. 2020;108:253-63. doi: 10.1002/cpt.1856.

18. Gianfrancesco M, Hyrich KL, Al-Adely S, Carmona L, Danila MI, Gossec L, et al; COVID-19 Global Rheumatology Alliance. Characteristics associated with hospitalisation for COVID-19 in people with rheumatic disease: data from the COVID-19 Global Rheumatology Alliance physician-reported registry. Ann Rheum Dis. 2020;79:859-866. doi: 10.1136/ annrheumdis-2020-217871.

19. Ferro F, Elefante E, Puxeddu I, Baldini C, Bartoloni E, Barate C, et al. COVID-19: the new challenge for rheumatologists. First update. Clin Exp Rheumatol. 2020;38:373-82.

20. Mathian A, Mahevas M, Rohmer J, Roumier M, Cohen-Aubart F, Amador-Borrero B, et al. Clinical course of coronavirus disease 2019 (COVID-19) in a series of 17 patients with systemic lupus erythematosus under long-term treatment with hydroxychloroquine. Ann Rheum Dis. 2020;79:837-9. doi: 10.1136/annrheumdis-2020-217566.

21. Holubar J, Le Quintrec M, Letaief H, Faillie JL, Pers YM, Jorgensen C. Monitoring of patients with systemic lupus erythematosus during the COVID-19 outbreak. Ann Rheum Dis. 2020. doi: 10.1136/annrheumdis-2020-217919.

22. Grange L, Guilpain P, Truchetet ME, Cracowski JL, French Society of $\mathrm{P}$, Therapeutics. Challenges of autoimmune rheumatic disease treatment during the COVID-19 pandemic: A review. Therapie. 2020;75:335-42. doi: 10.1016/j. therap.2020.06.013

23. Yao X, Ye F, Zhang M, Cui C, Huang B, Niu P. In vitro antiviral activity 551 and projection of optimized dosing design of hydroxychloroquine for the 552 treatment of severe acute respiratory syndrome coronavirus 2553 (SARS-CoV-2). Clin Infect Dis. 2020.

24. Mehta P, Mcauley D, Brown M, Sanchez E, Tattersall R, Manson J, et al. Correspondence COVID-19: consider cytokine storm syndromes and. Lancet. 2020;6736(20):19-20. 